\title{
INFLUÊNCIA DA COBERTURA VEGETAL NA VAZÃO DA PARTE ALTA DO RIO MUNDAÚ, PE/AL
}

\author{
Elaynne Mirele Sabino de França ${ }^{(a)}$, Suzana de Araújo Silva ${ }^{(b)}$ \\ (a) Pós-Graduação em Geografia-PPGEO/Universidade Federal de Sergipe, emirele.franca@ gmail.com \\ (b) Pós-Graduação em Desenvolvimento e meio Ambiente-PRODEMA/Universidade Federal de Pernambuco, \\ suzana.araujo.upe@hotmail.com
}

Eixo: Uso e ocupação das terras e legislação ambiental

\begin{abstract}
Resumo
A vegetação exerce diferentes benefícios para os componentes fisicos, destacando a água, cabe refletir sobre a influência da cobertura vegetal na vazão, seja no aumento ou redução. Na parte alta do Rio Mundaú em Pernambuco e Alagoas, foram obtidos registros da vazão média anual através da ANA e imagens LANDSAT para estimar a presença da vegetação em 1991, 2004 e 2014. O processamento dos dados ocorreu com os softwares Hidro 1.2 e Arcgis 10.3. A vazão apresentou aumento considerável na bacia hidrográfica, principalmente a partir dos anos 2000. Houve redução pouco significativa do tapete vegetal para os dois primeiros anos, pois a presença da vegetação estava com $255 \mathrm{Km}^{2}$ e $253 \mathrm{Km}^{2}$, respectivamente, numa expressão de $9 \%$ da área. Ao serem confrontados com 2014, é notório o aumento da porção vegetal para $753 \mathrm{Km}^{2}$, correspondendo a $26 \%$ em contrapartida dos $9 \%$ assim como houve redução da vazão, no mesmo período.
\end{abstract}

Palavras chave: Bacia hidrográfica; vegetação; Vazão média.

\section{Introdução}

Atualmente a água tem-se tornado tema de grande relevância no campo das discussões, sob diferentes contextos, em diversas instituições sociais, fomentando debates constantes, visto que nos últimos cinco anos a mídia televisa e jornais vêm enunciando alteração da dinâmica dos rios intermitentes e o colapso de reservatórios ao verem reduzidas suas quantias, isso enseja sinais de alerta já que a água tem entres as múltiplas finalidades, o abastecimento humano.

A preocupação extrapola além do presente, pois vem trazendo tendências e consequências positivas e negativas quanto aos recursos hídricos. Estudos são realizados sobre diferentes perspectivas e interesses variados, visto que o quantitativo de água serve tanto a população quanto a produção industrial e agrícola.

Isso reflete de vários fatores, enfatizando aqueles referidos a ação antrópica, desde a retirada ou modificação da cobertura vegetal até mesmo práticas descompromissadas em atender a legislação dos recursos hídricos (LEI 9.433/97) ou em observância a construção de um ambiente equilibrado e sustentável. 
Assim, surgiu interesse por saber da influência que a vegetação implica sobre a vazão de rios, visto que na literatura pesquisada de um lado temos a Lei $9.433 / 97$ e a Lei 12. 651/12 e os estudos realizados por alguns pesquisadores Hibbert (1967), Bosh e Hewlett (1982), Hsia e Koh (1983), Buytaert, Iñiguez e Bie`Vre (2007), Tucci e Clarke (1997), Moreira, Escada e Borma (2015), do qual apresentam posturas diferenciadas no que diz respeito a influência da vegetação na vazão de bacias hidrográficas.

Duas perspectivas diferenciadas se colocam aqui, uma em que a vegetação tem o papel de proteger e manter a condição ambiental da floresta e da água (LEI 9.433/97; LEI 12. 651/12) e a outra aponta que a remoção da vegetação aumentaria a quantidade da vazão, mesmo que temporariamente. No qual foi seguida a segunda reflexão na realização dessa pesquisa.

A luz dessa perspectiva, Hibbert (1967) generalizou três conjecturas: a redução da cobertura florestal aumenta o rendimento de água; o reflorestamento diminui a produção de água; a resposta ao tratamento é altamente variável e, na sua maior parte, imprevisível. Essas pressuposições foram utilizadas no fim da discussão dos resultados, a saber, o que foi constatado para essa bacia estudada.

O presente estudo diz respeito a analisar se haveria a ocorrência de influência da cobertura vegetal nas quantias de vazão do alto curso do Rio Mundaú localizado no estado de Pernambuco e Alagoas, a partir da comparação entre a vegetação e vazão.

\section{1 Área de estudo}

A parte alta da bacia hidrográfica fica situada no agreste de Pernambuco e Alagoas, onde integra o médio e baixo curso do Rio Mundaú para desemboca no litoral alagoano. A área estudada, destacada na figura 1, possui área $2.855 \mathrm{~km}^{2}$ dos $4.101 \mathrm{~km}^{2}$ correspondente a área total que abrange a bacia hidrográfica do Rio Mundaú.

Abrangendo um total de 16 municípios nos limites territoriais de Pernambuco (Angelim, Brejão, Caetés, Calçados, Canhotinho, Capoeiras, Correntes, Garanhuns, Jucati, Jupi, Jurema, Lagoa do Ouro, Lajedo, Palmeirina, Quipapá e São João) e 6 municípios do estado de Alagoas (Chã Preta, Ibateguara, Quebrangulo, Santana do Mundaú, São José da Laje e União dos Palmares).

Essa área da bacia foi escolhida por conta da disposição necessária de dados e registros imprescindíveis ao desenvolvimento dos objetivos propostos. Então, o ponto de delimitação da parte alta da bacia do Rio Mundaú partiu da localização do posto fluviométrico situado no munícipio de União dos Palmares em Alagoas. 

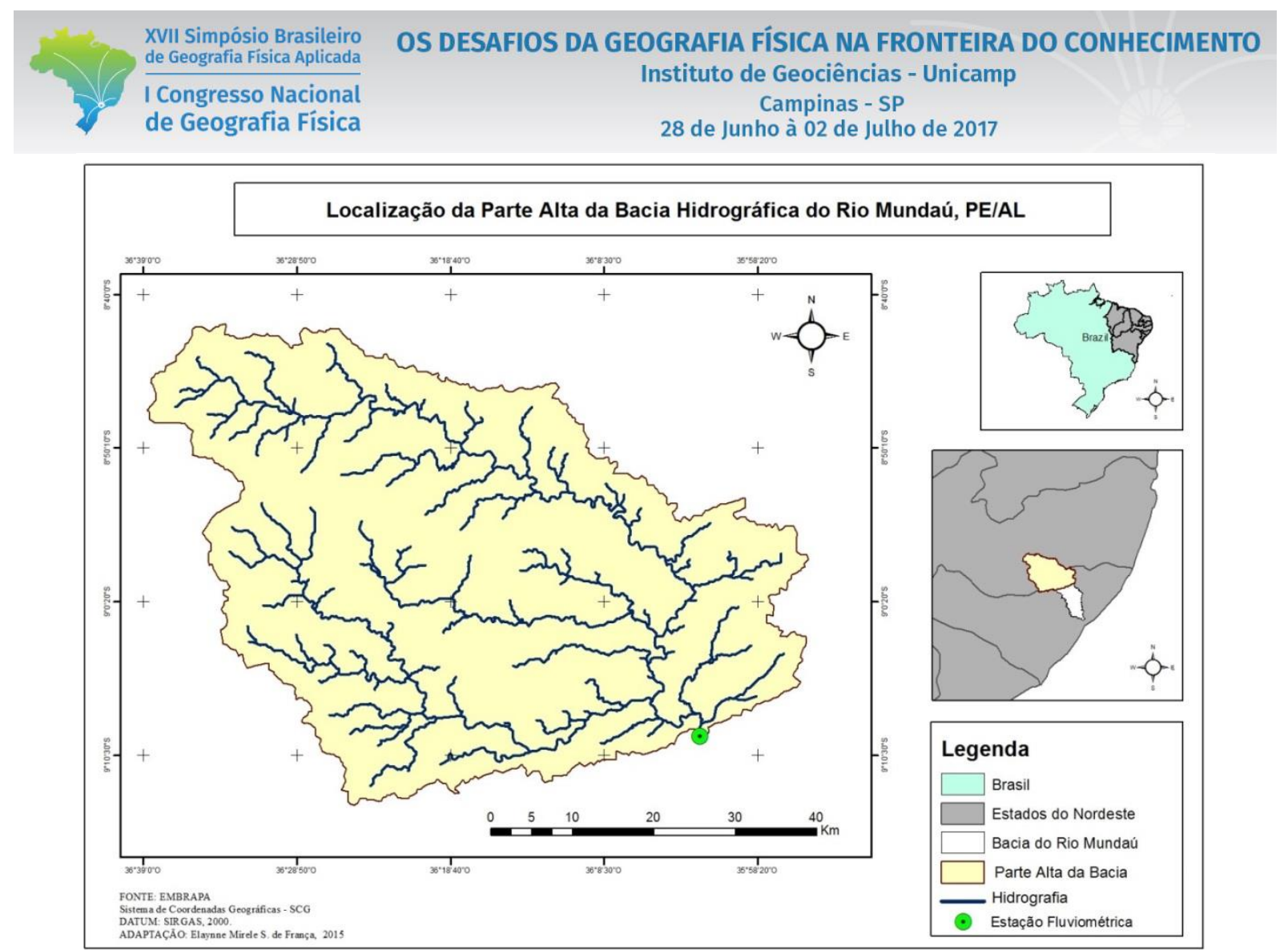

Figura 1 - Localização da parte alta da bacia hidrográfica Rio Mundaú, em Pernambuco e Alagoas.

Em análise moformétrica de toda área da bacia hidrográfica do Rio Mundaú Gomes (2014, 174-180) indicou a hipsometria em valores minímos e máximos de altitude em metros considerando a subdivisão da bacia. Na parte do Alto Mundaú com 174 e 1010m, Canhoto em 220 e 970m, Inhaúmas teve 220 e 880m, respectivamente, essas apresentam padrões estruturais de "cristas e relevos residuais" e o Médio Mundaú no "Complexo Belém de São Francisco". A parte do Alto Mundaú está acentado sobre a estrutura geológica do Planalto da Borborema, apresentando resitência pela ação erosiva e intemperismos, mas essa característica influência na capacidade impermeabilização pelas rochas presentes nesse arranjo estrutural.

\section{Metodologia}

Fez-se necessário levantamento na literatura de artigos científicos, livros, revistas e periódicos, dissertações e teses, que foram imprescindíveis a construção teórica e realização de todos os procedimentos operacionais. Também a busca por dados quantitativos em instituições de órgãos governamentais por meio de endereço eletrônico.

E por seguinte a organização e confecção dos dados das séries históricas da vazão média anual e processamento digital dos registros que resultaram a cobertura vegetal, para isso fez pré-processamento 
das imagens e por seguinte aplicação do NDVI que subsidiou a classificação da presença ou não da vegetação.

\subsection{Dados das séries históricas da vazão média}

De posse do conjunto de dados referentes aos números de séries históricas da vazão média mensal da estação fluviométrica localizada no município de União dos Palmares - AL de código 39740000 na latitude -9: 9: 16 e longitude -36: 2 :9, abrangendo uma área $2900 \mathrm{~km}^{2}$ tendo como responsável a ANA (Agência Nacional de Águas) e a entidade operadora o CRPM (Serviço Geológico do Brasil).

A área de estudo aqui considerada teve como primeiro critério, a localização da estação que disponibilizasse dados fluviométricos referentes a região escolhida, nisso o alto curso se enquadrou na decisão.

No software Hidro 1.2 foi descarregado os dados disponíveis no sítio eletrônico da ANA (http://hidroweb.ana.gov.br/) e ajustada para planilha. Exportados para o Excel para elaboração dos gráficos de dados fluviométricos da vazão média anual.

\subsection{Cobertura Vegetal}

A princípio precisou fazer pré-processamento das imagens para minimizar as distorções presentes e ajustar as bandas ao mesmo padrão geométrico, radiométrico e de reflectância. O processamento foi realizado no Arcgis 10.3.

A composição das bandas das imagens LANDSAT, utilizando as ferramentas disponíveis no Arctoolbox, com a banda 5 (1,55 a 1,75 $\mu \mathrm{m}$ - infravermelho médio), 4 (0,76 a 0,90 $\mu \mathrm{m}$ - infravermelho próximo) e 3 (0,63 a $0,69 \mu \mathrm{m}$ - vermelho) respectivamente, no formato RGB representam melhor características e representação espacial da vegetação, solo e água disposta na superfície terrestre.

No melhoramento e equalização das bandas espectrais pelas diferenças radiométricas identificadas, realizou-se uma correção e manipulação do contraste pelo histograma, no qual pode ser alterada cada quantia das bandas e assim eliminar variações entre os dados.

Foi necessário aplicar no mosaico das imagens em linha de corte (Feather), pois os dados rasterizados da United States Geological Survey (USGS) apresentam variações nas bordas direita e esquerda, ArcToolBox - Mosaic Dataset - Create Referenced Mosaic Dataset, no qual com a sobreposição pode-se observar a diminuição e supressão das inconstâncias nelas presentes. 
Por fim dessa etapa de tratamento, fez-se o registro das imagens a partir da identificação de pontos de controle relacionados à imagem base, a chamada Geocover, podendo ser adquirida no site da USGS (http://earthexplorer.usgs.gov/).

Após registro da imagem, foi escolhido o Sistema de Referência Geocêntrico para as Américas (SIRGAS) 2000.

\subsection{1 Índice de Vegetação por Diferença Normalizada (NDVI)}

O NDVI foi proposto por Rouse at. al. (1973). Ele é calculado pela diferença da reflectância entre a faixa do infravermelho próximo ( $p \mathrm{IVP})$ e a faixa do vermelho $(p \mathrm{~V})$. Onde essa diferença é normalizada pela divisão entre a diferença e soma das faixas de $p \mathrm{IVP}-p \mathrm{~V}$ (PONZONI; SHIMABUKURO; KUPLICH, 2012)

É compreendida pela seguinte equação:

$$
\mathrm{NDVI}=(p \mathrm{IVP}-p \mathrm{~V}) /(p \mathrm{IVP}+p \mathrm{~V})
$$

Onde:

NDVI - Índice de vegetação por diferença normalizada;

pIVP - Reflectância da faixa do infravermelho próximo;

$p \mathrm{~V}$ - Reflectância da faixa do vermelho.

Como é o resultado da combinação de duas bandas, "o NDVI cobre parcialmente os efeitos de presença dos constituintes atmosféricos e das perturbações radiométricas e geométricas” (HOLBEN, 1986, p.220)

O NDVI tem valor que varia de $-1 \mathrm{a}+1$, onde: Os valores negativos representam as nuvens, corpo hídrico; os valores ao redor de zero representam solo exposto ou sem vegetação; valor maior que zero representa a vegetação.

\subsubsection{Classificador Máxima Verossimilhança (Maxver)}

Para realização da classificação fez uso da metodologia supervisionada, com utilização do método estatístico Maxver (Máxima Verossimilhança), no qual é apontado nos estudos de Profeta (2015) como técnica eficiente na determinação e espacialização dos tipos uso e cobertura do solo, o próprio IBGE (2013) faz uso em seu manual. 
A classificação supervisionada é realizada por meio de métodos fundamentados em classificadores que usam as funções estatísticas para realizar analises e comparações entre as características das reflectâncias espectrais dos pixels com as características de uma determinada classe de padrão para classificar e delinear as classes das imagens digitais.

Liu (2006) diz que a classificação de máxima verossimilhança (Maxver) se constitui o método de classificação supervisionada mais usada no processo de identificação e delimitação das classes.

Foram utilizados os seguintes indicadores ou classes chaves para realizar a classificação da cobertura vegetal na área de estudo, disposta da seguinte maneira: Vegetação (V) e Não Vegetação (NV) (ALMEIDA, 2007; LINHARES, 2005).

Essas duas classes atendem basicamente a intenção ao qual o estudo se propõe, correspondendo de forma satisfatória e também pelo fato das imagens gratuitas disponíveis do satélite LANDSAT apresentar uma resolução de 30 metros.

\section{Resultados e Discussões}

Os resultados obtidos foram dispostos em duas partes: primeiro sobre à vazão média anual do período de 1990 a 2014, através de gráfico representativo da regressão linear evidenciando a tendência de vazão com recorte temporal dos últimos vinte e quatro anos; e depois a quantificação multitemporal da cobertura vegetal.

\subsection{Vazão}

Os dados da estação fluviométrica expõem a quantia de vazão em metros cúbicos por segundo registrada durante os anos para área de abrangência da bacia hidrográfica em estudo, onde foram dimensionados na figura 2 a seguir: 


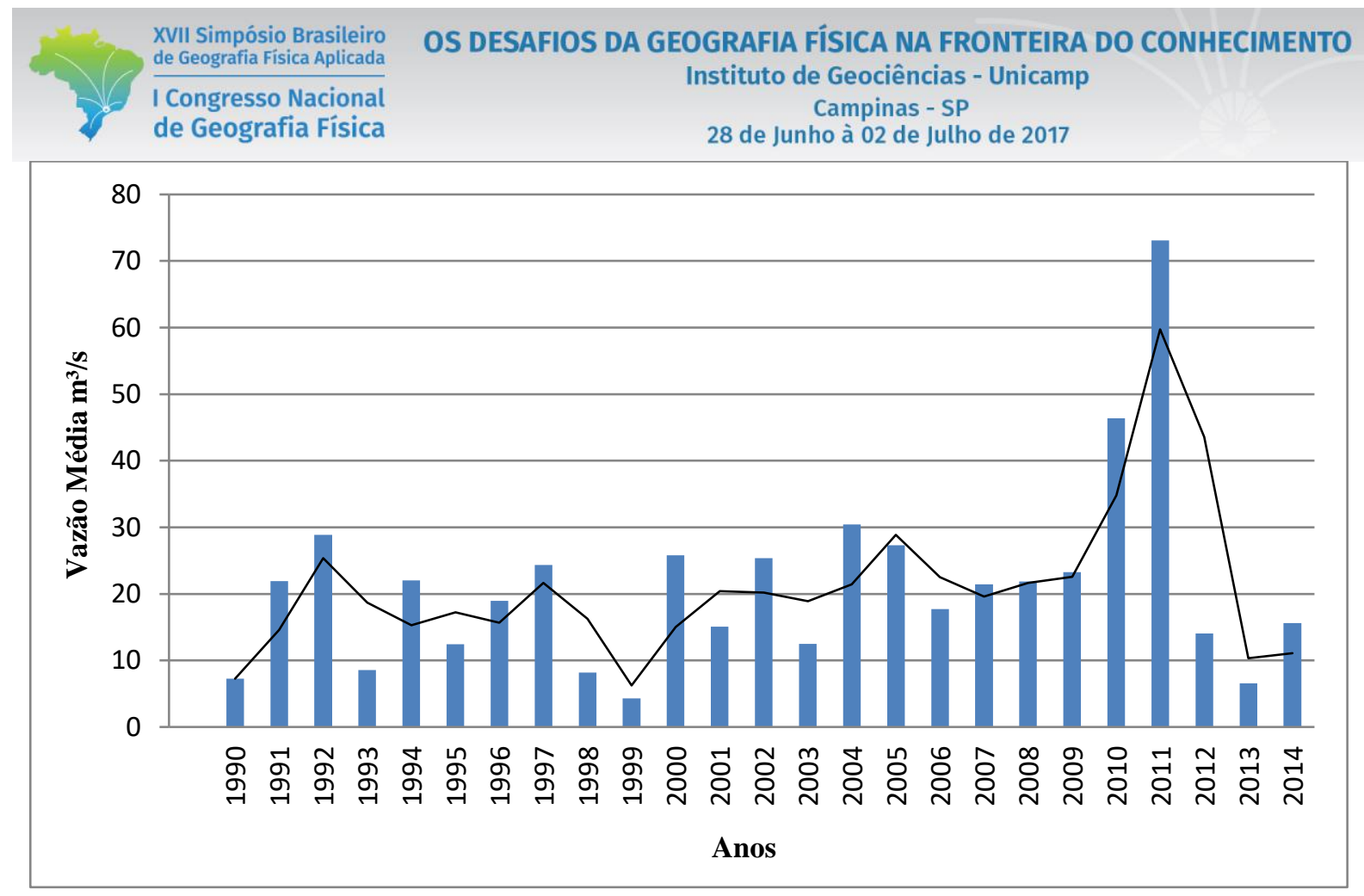

Figura 2: Resultado quantitativo das vazões médias constatadas para cada ano.

No que ficou demonstrado pelo referido gráfico acima, pouco são os anos em que se obteve uma vazão aproximada ou inferior a $10 \mathrm{~m} 3 / \mathrm{s}$, um total de cinco, sendo apresentado o menor índice de vazão observado em 1999 quando teve uma quantidade de 4,291 m³/s na média anual.

Bem, cabe aqui destacar os registros obtidos nos anos de 2010 e 2011, na análise considerando os vinte e quatro anos representados no gráfico, não foram apontados índices semelhantes à quantia de 46, 395 e $73,077 \mathrm{~m} 3 / \mathrm{s}$ respectivamente em todo o período.

O ano de 2010 foi marcado por ter ocorrido grande evento de chuvas que ocasionaram enchentes na bacia hidrográfica atingindo várias cidades, principalmente aquelas que possuíam maior proximidade aos cursos d’água, provocando a destruição de casas, igrejas, áreas comerciais, pontes e etc. A situação chegou a ponto de haver a necessidade de relocação da população para áreas seguras, a exemplo disso à cidade União dos Palmares - AL, além do prejuízo econômico houve também a perda de vidas.

O volume de água e a força devastou tudo o que encontrou pela frente. E mesmo assim observando a figura 1, o topo da vazão não foi no ano de ocorrência da enchente, mas no ano seguinte em 2011 apresentou maior índice de vazão com $73,077 \mathrm{~m} 3 / \mathrm{s}$ registrado no período, esse valor talvez pudesse ser aumentado visto que os equipamentos do posto fluviométrico foram carregados pelas águas e não pode ser feita a medição posteriormente.

Da Silva (2009) faz menção a essa característica peculiar considerando a região propícia a episódio de secas ou enchentes. Destacando os condicionantes atmosféricos responsáveis pela produção de chuvas no 


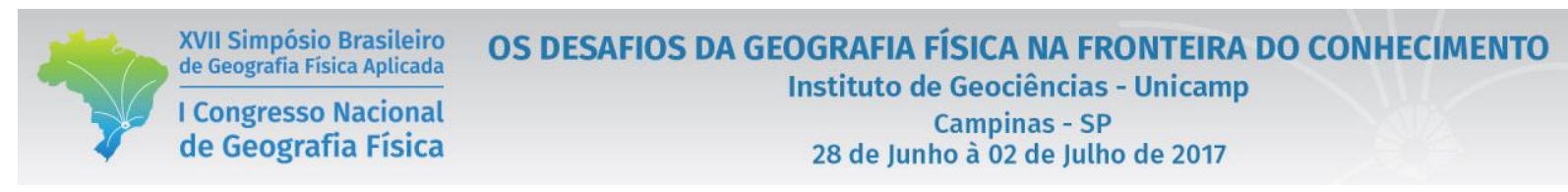

Nordeste estão relacionados à Temperatura Superficial do Mar do Atlântico Sul (TSM) e o posicionamento em que se encontra a Zona de Convergência Intertropical (ZCIT), promotores da distribuição chuvas na região.

O Centro de Previsão de Tempo e Estudos Climáticos já evidenciava em seus boletins a atuação do El Niño numa fase de esfriamento e consequentemente apresentava o desenvolvimento de outro fenômeno, a La Niña no Pacífico, o aquecimento das águas Atlântico Norte, junto às oscilações dos ventos alísios de leste formaram o quadro que contribuiu para episódios de chuvas intensas, contribuindo para vazão da bacia.

Quando destacado a vazão para os anos de 1991 com vazão 21, 839 m³/s, 2004 com 30, 425 m³/s e 2014 de $15,591 \mathrm{~m} 3 / \mathrm{s}$, há uma variação de entre os dois primeiros antes do episódio da enchente e, posterior a esse, em 2014 houve redução próximo da metade comparado a 2004.

\subsection{Cobertura Vegetal}

A partir do mapeamento da vegetação nas figuras 3, 4 e 5 pode ser especializado e quantificado a os valores correspondentes a bacia hidrográfica estudada.
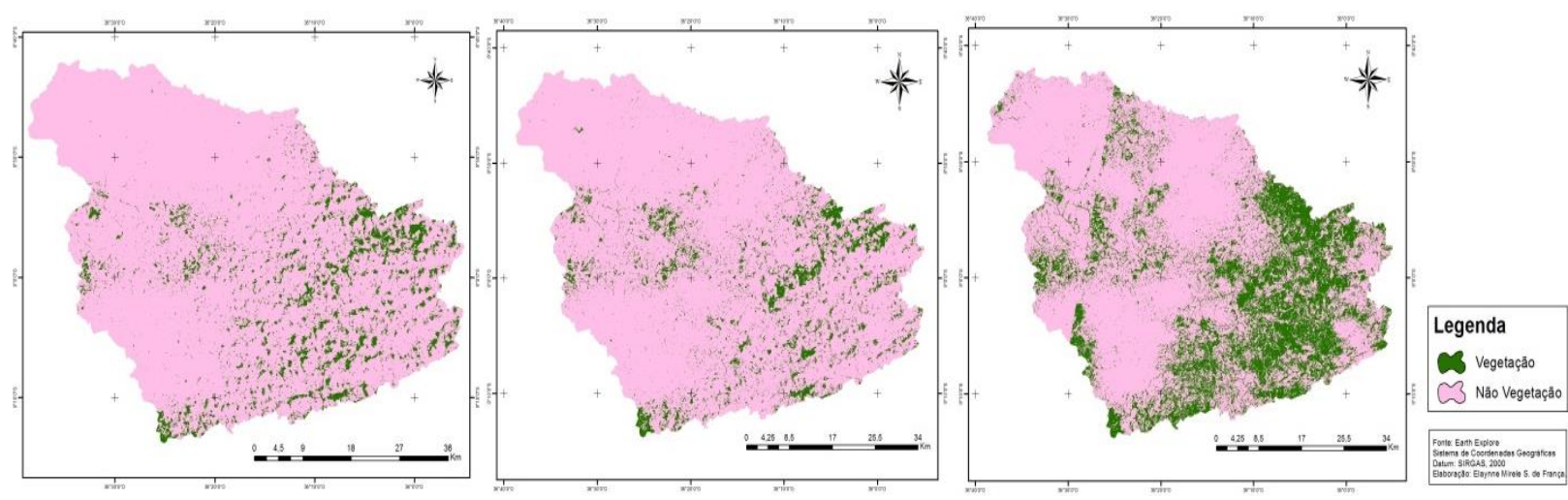

Figura 3, 4 e 5: Área com vegetação e sem vegetação para os anos, respectivamente, de 1991, 2004 e 2014,

A expressão de cobertura vegetal vista 1994 corresponde ao valor de $255 \mathrm{~km}^{2}$ de extensão, para o ano de 2004 a parte de vegetação na superfície correspondia a $253 \mathrm{~km}^{2}$ o que equivale dizer para as duas datas um percentual de $9 \%$ da área. E 2014 com área de $753 \mathrm{~km}^{2}$ de cobertura vegetal. 
Tabela I - Quantia de cobertura vegetal, respectivamente, em 1991, 2004 e 2014 dado no período de seco e chuvoso.

\begin{tabular}{lccc}
\hline \multirow{2}{*}{ ANOS } & \multicolumn{2}{c}{ CLASSES } & RESULTADO \\
& \multicolumn{2}{c}{} & \\
\cline { 2 - 4 } & Vegetação (V) & Não Vegetação (NV) & Percentual V - NV (\%) \\
\hline $\mathbf{1 9 9 1}$ & $255 \mathrm{Km}^{2}$ & $2.600 \mathrm{Km}^{2}$ & $9 \%-91 \%$ \\
$\mathbf{2 0 0 4}$ & $253 \mathrm{Km}^{2}$ & $2.602 \mathrm{Km}^{2}$ & $9 \%-91 \%$ \\
$\mathbf{2 0 1 4}$ & $753 \mathrm{Km}^{2}$ & $2.102 \mathrm{Km}^{2}$ & $26 \%-74 \%$ \\
\hline
\end{tabular}

Notável diferença em relação aos anos de 1991 e 2004, que obtiveram um total de nove por cento de vegetação em comparação aos $26 \%$ de 2014 , marcando diferença entre esses de dezessete por cento, como é mostrado nos valores da tabela I e especializado nas figuras 3, 4 e 5.

Cabe lançar aspectos que podem ter contribuído para a ocorrência dessa expressiva diferença ocasionada entre os dois primeiros anos da pesquisa e o terceiro, diz respeito ao período em que foram utilizadas as imagens de satélite, as primeiras sendo no mês de Dezembro e a de 2014 em Março, período no qual pode haver maior reflexão espectral da vegetação.

Para isso ter ocorrido, episódios de chuva nesse período fizeram com que a vegetação manifestasse, a partir das folhas, a vitalidade que possui. Conforme Liu (2006), a vegetação tem diferentes tipos de reflectância que podem ser captados pelos sensores, pois a condição das folhas, tomando como característica a idade ( $1^{\circ}$ ano, $2^{\circ}$ ano, $3^{\circ}$ ano e outros) coloração (folha verde, amarela e vermelha), período de secagem das folhas e nível em que se encontra a cobertura vegetal (folha da floresta, folha de plantação) pode ter contribuído para o resultado final.

Salientando para época, na região acontece o plantio em grande parte da região de agriculturas temporárias: milho e feijão, como também as que têm período diferenciado para seu desenvolvimento e colheita, em si tratando da cana-de-açucar.

Para os anos de 1991 e 2004, como pode ser vista na tabela I, não há diferença significativa quanto os valores da presença ou não da vegetação, fato que em 2014 o resultado da vegetação realiza uma ascendência relevante de cobertura vegetal. 
XVII Simpósio Brasileiro de Geografia Fisica Aplicada

I Congresso Nacional de Geografia Física
OS DESAFIOS DA GEOGRAFIA FÍSICA NA FRONTEIRA DO CONHECIMENTO

Instituto de Geociências - Unicamp

Campinas - SP

28 de Junho à 02 de Julho de 2017

\subsection{Confrontando os resultados e pressuposições de Hibbert (1967)}

Apreciando os resultados da vazão na bacia hidrográfica, as evidências da figura 6 demonstram que ocorreu aumento do escoamento superficial das águas entre $1991 \mathrm{com} \mathrm{8,623} \mathrm{m³/s} \mathrm{e} 2004$ foi para 24,823 $\mathrm{m}^{3} / \mathrm{s}$ no período seco, havendo redução em 2014 quando atingi $15,716 \mathrm{~m} 3 / \mathrm{s}$.

$\mathrm{Na}$ época chuvosa, os primeiros anos mantêm vazões aproximadas, com $35,164 \mathrm{~m}^{3} / \mathrm{s}$ e $36,029 \mathrm{~m}^{3} / \mathrm{s}$ e em 2014 demonstra queda da vazão para $15,518 \mathrm{~m}^{3} / \mathrm{s}$.

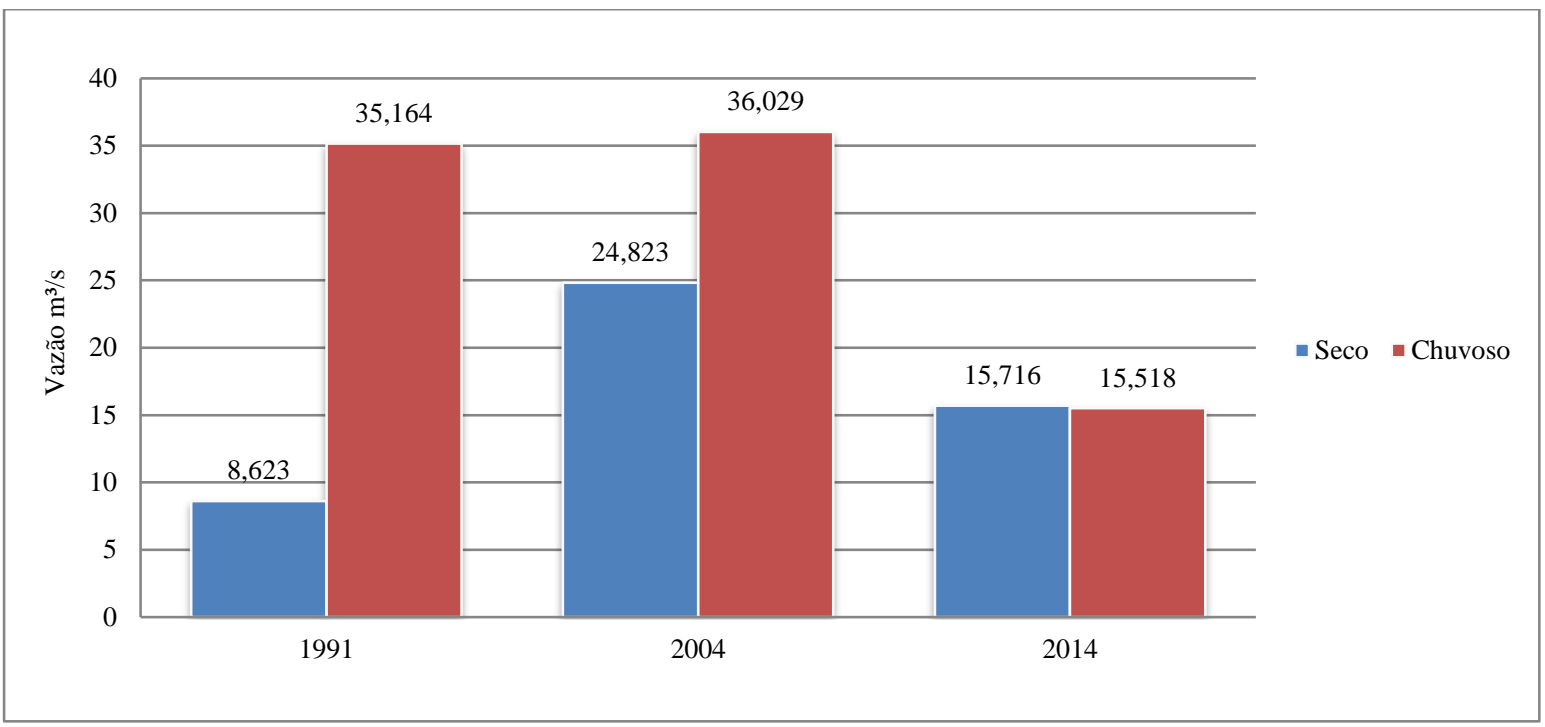

Figura 6: Vazões médias constatadas para os anos de 1991, 2004 e 2014 dadas, respectivamente, no período de seco e chuvoso.

A vegetação mantém valor aproximado em 1991 e 2004, diferenciados por 2 Km² de área, e 2014 com diferença somada de $500 \mathrm{Km}^{2}$, total de $753 \mathrm{Km}^{2}$, de abrangência de cobertura vegetal presente na superfície da bacia.

Infere-se que a redução da vazão para os dois períodos em 2014 é correspondido pelo aumento da vegetação na bacia hidrográfica. Então, a redução contribuiu para o aumento do rendimento de água.

Essa consideração aponta também para o pressuposto de que o reflorestamento seria indicativo da diminuição da quantia de água.

E por fim, demonstrando a capacidade dos recursos tecnológicos atualmente disponíveis contribui para montar uma previsão tendencial da ocorrência ou não de um fenômeno e sua variabilidade está relacionada aos aspectos que dizem respeito aos dados e períodos que são utilizados, a qualidade dos registros que puderam ser analisados e outros. 


\section{Considerações Finais}

Chegando à constatação da vazão média ter passado por momento de aumento e reduções observadas nos anos analisados, sendo que a partir de 2000 apresentou picos altos históricos nunca antes registrados nos vinte e quatros.

A cobertura vegetal demonstrou-se constante em expressão espacial, pois em 1991 e 2004 tiveram resultados aproximados, e posteriormente em 2014 o aumento que conciliou com época de redução da vazão média. Esse fato faz indicativo para dizer que, com a redução da vegetação aumenta a vazão, já que diz respeito a água presente em outras condições, além da vazão.

Das variáveis utilizadas, não ter vegetação e ter vegetação, caberia em outro momento considerar o tipo de vegetação a qual está sendo referida, pois a região possui calendário de cultivos agrícola (temporárias) e atividades pecuárias (pastagem) que tem parcela de contribuição para poder melhor especificar a influência direta na relação da vazão e cobertura vegetal. Sendo necessário estudo com uma ampliação da série histórica.

Os resultados são satisfatórios no tocante ao objetivo a que se propôs o estudo e pode contribuir para analisar e refletir sobre os pressupostos elencados. Acredita-se ser previsível realizar uma estimativa sobre as variáveis aqui estudadas e fornecer auxílio ao planejamento ambiental.

\section{Bibliografia}

BRASIL. Lei, 12.651. Novo Código Florestal de Maio de 2012. Disponível em: http://www.planalto.gov.br/ccivil_03/_ato2011-2014/2012/lei/l12651.htm. Acesso em: 03 ago. 2014.

BRASIL. Lei, 9.433. Política Nacional dos recursos hídricos de Janeiro de 1997. Disponível em: http://www.planalto.gov.br/CCIVIL_03/leis/L9433.htm. Acesso em: 03 ago. 2014.

BOSH, J. M; HEWLETT, J. D. A Review of Catchment Experiments to Determine The Effect of Vegetation Changes on Walter Yiel and Evapotranspiration. Elsevier Scientific Publishing Company, Amsterdam - Printed in the Netherlands. Jornal of hydrology, 55, 1982. p. 3-23

BUYTAERT, W; INIGUEZ, V; BIE'VRE, B. de. The effects of afforestation and cultivation on water yield in the Andean páramo. Forest Ecology and Management. 2007.

DA SILVA, D. F. Análise de Aspectos Climatológicos, Agroeconômicos, Ambientais e de seus Efeitos sobre a Bacia Hidrográfica do Rio Mundaú (AL e PE). 2009. Tese (Doutorado em Recursos Naturais) - Universidade Federal de Campina Grande, Centro de Tecnologia e Recursos Naturais.

GOMES, D. D. M. Análise e Compartimentação Moformétrica da Bacia Hidrográfica do Rio Mundaú - Pernambuco e Alagoas. Revista de Geologia, v.27, n2, p.167-182, 2014.

HIBBERT, A. R. Forest Treatment Effects on Water Yield. 1967, p. 527-543.

HSIA, Y.J.; KOH, C.C. Water yield resulting from clearcutting a small hardwood basin in central Taiwan. Hydrology of Humid Tropical Regions with Particular Reference to the Hydrological Effects of Agriculture and Forestry Practice. IAHS, n. 140, 1983. p. 215-220. 
LIU, W. T. S. E. Índices de Vegetação. p. 215-242 In: LIU, W. T. S. E. Aplicações de Sensoriamento Remoto. Campo Grande: Editora Uniderp, 2006. p.881

MOREIRA, E. P.; ESCADA, M. I. S.; BORMA, L. de S. Efeitos da mudança da cobertura florestal na vazão de uma sub-bacia na porção leste da Amazônia. Anais XVII Simpósio Brasileiro de Sensoriamento Remoto - SBSR, João Pessoa-PB, Brasil, 25 a 29 de abril de 2015. p.7103-7110.

PONZONI, F. J. SHIMABUKURO, Y. E. KUPLICH, T. M. Sensoriamento Remoto da Vegetação. $2^{a}$ ed. Revisada e ampliada. São Paulo: Oficina de Textos, 2012.

TUCCI, C. E. M.; CLARKE, R. T. Impacto das mudanças da cobertura vegetal no escoamento: revisão. Revista Brasileira de Recursos Hídricos, v.2, n1 JAN/JUN, 1997. p.135-152. 